\title{
How Long Do the Consequences of Parental Preference Last: A Study of Twins From Pregnancy to Young Adulthood
}

\author{
L. Tuulikki Trias,' Hanna E. Ebeling,' Varpu Penninkilampi-Kerola, ${ }^{1,2}$ Anne M. Kunelius,' Tiina T. Tirkkonen,' \\ and Irma K. Moilanen' \\ ' Clinic of Child Psychiatry, Department of Paediatrics, University and University Hospital of Oulu, Oulu, Finland \\ ${ }^{2}$ Clinic of Child Psychiatry, Department of Paediatrics, University of Oulu, Oulu, Finland, and Department of Public Health, University of Helsinki, Finland
}

W e analyzed depressive and psychosomatic symptoms in relation to parental preference in 419 twins at the age of 22 to 30 years. Depressiveness was elicited with Children's Depression Inventory and reported as a total score and three subscales (low self-confidence, anhedonia and sadness) based on factor analysis as reported in a previous epidemiological study conducted in Finland. Items assessing nervous complaints and somatic symptoms were adapted from Finnish studies of juvenile health habits. Twins reported the preference in two directions: experienced parental preference towards either twin, and twin's own preference towards either parent. About half of the twins were from pairs where both twins experienced having been equally close to both parents, while about 30\% were from 'equal and mother's' pair, where one twin evaluated having been preferred by the mother and the co-twin evaluated having been equally close to both parents. According to the twins' own preference, about one third of the twin pairs were 'both equal', one third 'both mother's' and one third 'equal and mother's'. Those male twins who were equally close to both parents (experienced parental preference) had least total depressiveness, while females in the intermediate situation had the highest self-confidence and least anhedonia and nervousness. According to twins' own preference, twins who felt equally close to both parents had the least depressiveness and anhedonia. The intermediate position seems to be the best alternative, as these twins had the least symptoms.

Parenting twins differs from parenting singletons. Differences begin during pregnancy and are found in the infant-parent relationship as well as in twins' social-emotional development. Parents may experience a feeling of privilege, as around only one expectant mother in 80 will give birth to twins. On the other hand, awareness of the special risks involved in a twin pregnancy and delivery may cause additional stress (Holditch-Davis et al., 1999).
The twin situation has been shown to be influential in shaping parent-child interaction, particularly in its impact on parent socialization practices (Lytton, 1980). As the mother may have difficulties coping alone while taking care of two infants the father may become increasingly important in looking after the children. It often happens that the father takes responsibility for nursing one of the babies while the mother takes over the other one (Moilanen \& Pennanen, 1997). This is how the situation with a 'mother's twin' and a 'father's twin' begins. Some studies show the ways in which postnatal medical complications may lead to preference on the part of the mother for one of the twins. While the study of seriously premature twins (weight $<1501 \mathrm{~g}$ ) by Minde et al. (1990) showed that mothers tended to prefer the stronger, more medically sound twin, in another study of only slightly premature and healthy twins, preference based on perinatal difficulties was rare (Robin et al., 1992). In some studies mothers developed a closer bonding with the weaker or ailing twin (Allen et al., 1971; Moilanen \& Pennanen, 1997).

The solution of 'sharing the twins' as mother's and father's twin has been suggested to promote the individual development of the twins and to relieve mutual rivalry between them, as each has his or her own parent as an object of identification and attachment (Allen et al., 1971). In contrary to Allen et al. (1971), Sheehan (1997) suggested that parental favouritism appears to create a rivalrous dynamic between siblings or in the twin relationship, affecting the quality of the sibling relationship as a whole. Furthermore, this kind of division into 'mother's child' and 'father's child' does not seem to be beneficial in all cases as so-called 'mother's twins' have been shown to have the highest prevalence of mild psychiatric and psychosomatic

Received 4 October, 2005; accepted 24 January, 2006.

Address for correspondence: Tuulikki Trias, Clinic of Child Psychiatry, Department of Paediatrics, University and University Hospital of Oulu, P.O.Box 26, Fin-OYS 90220, Oulu, Finland. E-mail: tuulikki.trias@luukku.com 
symptoms in adolescence in this same study sample, while least psychosomatic symptoms were seen in twins in the intermediate position (Moilanen \& Pennanen, 1997).

The present article focuses on the differences in parental preferences and their implications for the mental health of twins in their young adulthood, 22 to 30 years of age. Our aim was to examine whether parental preference was associated with depression or psychosomatic symptoms, and whether twins from different types of twin pairs reported symptoms differently in relation to parental preference.

\section{Subjects and Methods Participants}

The original study group is made up of all 335 twin deliveries in Oulu University Hospital during the years 1965 to 1973 (Koivisto et al., 1975). The twins have been followed at 10-year intervals, at 2 to 10 years of age, 12 to 20 years of age and now at 22 to 30 years of age. The data collection has been described in detail previously (Ebeling et al., 2003).

Zygosity was determined at two ages. In the first follow-up at 2 to 10 years of age, 1975 to 1976 , about one third of the twins were subjected to clinical examination, and determination of zygosity for these twins was based on similarity methods (Moilanen, 1979). Later, at the age of 22 to 30, during the present investigation, all twins received questionnaires with items of (1) "similarity - were you and your twin partner during childhood as like as "two peas in a pod" or were you of ordinary family likeness?' and (2) 'confusion - were you and your twin partner so similar in appearance before, at or after school age that people had difficulty in telling you apart?' (Sarna et al., 1978). These questions were used in the decision tree to determine zygosity: if both same-sex (SS) twins replied 'like two peas in a pod' and 'yes' to the question about people having difficulty in telling them apart at and after school age, they were considered monozygotic (MZ). Conversely, twins were regarded dizygotic (DZ) if they both replied 'of ordinary family likeness' and 'no' to questions about confusion in appearance at and after school age. If the answers about similarity and 'people having difficulty in telling twins apart' disagreed or at least one twin had replied 'don't know', zygosity was confirmed from the zygosity determination data at 2 to 10 years of age, available for one third of twins, while the rest remained in the group of unclassified cases $(n=75)$.

In the present study 419 twins returned the questionnaire. There were 201 males and 218 females; 184 complete pairs as well as 51 twins who were the only ones of the pair to respond. Zygosity was determined in 344 twins, 32 of whom were monozygotic males (MZM), 65 same-sex dizygotic males (SSDZM), 78 opposite-sex dizygotic males (OSDZM), 32 monozygotic females (MZF), 50 same-sex dizygotic females (SSDZF) and 87 opposite-sex dizygotic females (OSDZF).

\section{Methods}

At the present investigation in 1995, when the twins were 22 to 30 years old, they completed questionnaires about intertwin and parent-twin relationships and mental wellbeing. Parental preference was inquired of the twins in two directions: (1) experienced parental preference 'did you feel that either parent preferred you?', and (2) twin's own preference 'which one of the parents did you feel closer to?' The twins reported these two dimensions now, as young adults, and retrospectively, concerning ages before school and at school age, which in Finland includes the years from 7 to 16 (compulsory school age), or to 19 (upper secondary school).

Pairwise parental preference was formed on the basis of the responses of each individual co-twin of a pair to questions about experienced parental preference and twin's own preference. Twin pairs were classified into six categories: (1) both equal (both twins of a pair reported to be equally close to both parents), (2) opposite poles (one twin of a twin pair reported to be preferred by the mother and the co-twin reported to be preferred by the father), (3) both mother's (both twins of a pair reported to be preferred by the mother), (4) both father's, (5) equal and mother's (one twin evaluated to be preferred by the mother and the co-twin evaluated to be equally close to both parents) and (6) equal and father's. Pairwise twin's own preference was formed equally (Table 2).

Depressiveness scores were measured, as previously, by the Children's Depression Inventory (CDI; Kovacs, 1980). Twenty-six of the 27 items were used, now modifying the questions for this age, that is, replacing ' $I$ never have fun at school' with '... during studies or work'. The item about suicidal tendencies had been excluded from the previous inquiries for ethical reasons and was excluded here as well. The items were scored from 0 to 2 . In addition to total depressiveness, three subscores were formed based on a factor analysis performed on an epidemiological study in Finland (Moilanen, 1990). The factors were low self-confidence (items: I hate myself, nobody loves me, I look ugly, I am bad, I do everything wrong, I do very badly), anhedonia (items: nothing is fun, things bother me, I never have fun at my studies or at work), and sadness (items: I am sad all the time, I feel like crying, I feel lonely).

Items assessing nervous complaints and somatic symptoms were adapted, as previously, from previous Finnish studies of juvenile health habits (Rimpelä et al., 1983). Twins' self-reports of the symptom frequency were classified into four categories, the frequencies of which were evaluated by assigning four ordered values to occurrences 'never or less than monthly' $(0)$, 'monthly' (1), 'weekly' (2), and 'daily' (3). Nervous complaints were made up of nervousness, irritability and loss of energy, and somatic complaints of headache and abdominal pain (Moilanen, 1987).

The two measures of parental preference and their relation to depressive and psychosomatic symptoms were analyzed separately in both genders, in each 
Table 1

Distribution of Parental Preference by Zygosity and Gender as Reported by the Twins at the Age of 22 to 30 Years

\begin{tabular}{|c|c|c|c|c|c|c|c|c|c|}
\hline Twin's Age & Males & \multicolumn{6}{|c|}{ Females } & \multicolumn{2}{|c|}{ Total } \\
\hline Closer Parent & $\begin{array}{c}\text { MZM } \\
(n=32) \\
\%\end{array}$ & $\begin{array}{c}\text { SSDZM } \\
(n=63) \\
\%\end{array}$ & $\begin{array}{c}\text { OSDZM } \\
(n=78) \\
\%\end{array}$ & & $\begin{array}{c}\text { MZF } \\
(n=32) \\
\%\end{array}$ & $\begin{array}{c}\text { SSDZF } \\
(n=52) \\
\%\end{array}$ & $\begin{array}{c}\text { OSDZF } \\
(n=87) \\
\%\end{array}$ & $\%$ & $(n)$ \\
\hline \multicolumn{10}{|c|}{ Experienced parental preference } \\
\hline \multicolumn{10}{|l|}{ Before school } \\
\hline Mother & 6.3 & 16.7 & 28.6 & & 20.7 & 14.9 & 22.4 & 20.0 & (66) \\
\hline Equal & 93.8 & 81.7 & 63.6 & & 65.5 & 63.8 & 61.2 & 69.4 & (229) \\
\hline Father & 0.0 & 1.7 & 7.8 & 1 & 13.8 & 21.3 & 16.5 & 10.6 & (35) \\
\hline \multicolumn{10}{|l|}{ School } \\
\hline Mother & 6.5 & 19.7 & 34.2 & & 17.2 & 21.3 & 34.1 & 25.5 & (83) \\
\hline Equal & 90.3 & 77.0 & 63.2 & & 65.5 & 59.6 & 51.2 & 65.0 & (212) \\
\hline Father & 3.2 & 3.3 & 2.6 & 2 & 17.2 & 19.1 & 14.6 & 9.5 & $(31)$ \\
\hline \multicolumn{10}{|c|}{ Young adulthood } \\
\hline Mother & 20.0 & 16.4 & 39.0 & & 31.3 & 31.9 & 39.0 & 31.2 & (101) \\
\hline Equal & 76.7 & 80.3 & 55.8 & & 56.3 & 61.7 & 57.1 & 63.6 & (206) \\
\hline Father & 3.3 & 3.3 & 5.2 & 3 & 12.5 & 6.4 & 3.9 & 5.2 & (17) \\
\hline \multicolumn{10}{|c|}{ Twin's own preference } \\
\hline \multicolumn{10}{|l|}{ Before school } \\
\hline Mother & 34.4 & 45.9 & 53.2 & & 37.5 & 34.0 & 52.3 & 45.6 & (154) \\
\hline Equal & 59.4 & 49.2 & 37.7 & & 50.0 & 44.0 & 33.7 & 42.9 & (145) \\
\hline Father & 6.3 & 4.9 & 9.1 & & 12.5 & 22.0 & 14.0 & 11.5 & (39) \\
\hline \multicolumn{10}{|l|}{ School } \\
\hline Mother & 38.7 & 41.9 & 56.6 & & 50.0 & 56.0 & 71.4 & 55.2 & (185) \\
\hline Equal & 51.6 & 53.2 & 38.2 & & 31.3 & 24.0 & 16.7 & 34.0 & (114) \\
\hline Father & 9.7 & 4.8 & 5.3 & & 18.8 & 20.0 & 11.9 & 10.7 & $(36)$ \\
\hline \multicolumn{10}{|c|}{ Young adulthood } \\
\hline Mother & 41.9 & 24.6 & 46.1 & & 59.4 & 50.0 & 60.7 & 47.3 & (158) \\
\hline Equal & 51.6 & 72.1 & 48.7 & & 31.3 & 44.0 & 33.3 & 47.0 & (157) \\
\hline Father & 6.5 & 3.3 & 5.3 & 4 & 9.4 & 6.0 & 6.0 & 5.7 & (19) \\
\hline
\end{tabular}

Note: $M Z M=$ monozygotic male twins, SSDZM = same-sex dizygotic male twins, OSDZM = opposite-sex dizygotic male twins, MZF = monozygotic female twins, $S S D Z F=$ same-sex dizygotic female twins, OSDZF = opposite-sex dizygotic female twins.

Significant differences between SS (MZM and SSDZM) and OS males ${ }^{1} p=.003,{ }^{2} p=.056,{ }^{3} p=.003,{ }^{4} p=.021$. (Wald $F$ statistic for correlated data.)

zygosity group as well as in SS (MZ and SSDZ twins) versus opposite-sex (OS) twin pairs.

The mean values of the total depressiveness scores and subscores were presented. If data were missing in one third or less of the sum-variable items (low selfconfidence, anhedonia, sadness, nervous complaints and somatic complaints), the missing data were replaced by modes $(=0)$; otherwise the case was excluded from the analyses. To account for the fact that observations of twin pairs are correlated we used the complex survey data analysis methods in Stata 8.0 (StataCorp., 2003). To test the differences in proportions between different twin types and gender, differences in distribution and means were tested by using the Wald $F$ statistics for chi-square tests adjusted for correlated data (Rao \& Scott, 1984). As the distribution of depressiveness and psychosomatic symptom scores were positively skewed, they were classified into categorical variables for Stata analysis. In post hoc analysis comparing the differences between the means of the two groups, Bonferroni's test significance levels were used. The analyses were performed using SPSS (SPSS Inc., 2003; version 12.0) as well as Stata (StataCorp., 2003; version 8.0) programs.

\section{Results}

\section{Experienced Parental Preference}

Parental preference is presented in two directions: which one of the parents was reported to feel closer to the twin (experienced parental preference evaluated by the twin), and which one of the parents the twin felt closer to (twin's own preference). According to experienced parental preference, twins experienced most often to be equally close to both parents. After starting school, female twins in particular experienced being increasingly preferred by their mothers. However, when compared with males, females felt more often having been preferred by fathers before and during school age (Table 1). 
Table 2

Parental Preference and Zygosity Within Twin Pairs

\begin{tabular}{|c|c|c|c|c|c|}
\hline Favouritism & $\begin{array}{c}\mathrm{MZ} \\
\%(n, \text { pairs })\end{array}$ & $\begin{array}{c}\text { SSDZ } \\
\%(n, \text { pairs })\end{array}$ & $\begin{array}{c}\text { OSDZ } \\
\%(n, \text { pairs })\end{array}$ & $\begin{array}{c}\text { Total }^{1} \\
\% \text { (n, pairs) }\end{array}$ & $\begin{array}{l}\text { Grand total }{ }^{2} \\
\%(n, \text { pairs })\end{array}$ \\
\hline \multicolumn{6}{|c|}{ Experienced parental preference } \\
\hline Both equal & $55.6(15)$ & $57.8(26)$ & $33.3(21)$ & $45.9(62)$ & $47.0(77)$ \\
\hline Opposite poles & $3.7(1)$ & $4.4(2)$ & $4.8(3)$ & $4.4(6)$ & $3.7(6)$ \\
\hline Both mother's & $14.8(4)$ & $6.7(3)$ & $14.3(9)$ & $11.9(16)$ & $9.8(16)$ \\
\hline Both father's & $3.7(1)$ & $2.2(1)$ & 0.0 & $1.5(2)$ & $1.2(2)$ \\
\hline Equal and mother's & $14.8(4)$ & $26.7(12)$ & $44.4(28)$ & $32.6(44)$ & $32.9(54)$ \\
\hline Equal and father's & $7.4(2)$ & $2.2(1)$ & $3.2(2)$ & $3.7(5)$ & $5.5(9)$ \\
\hline Total & $100.0(27)$ & $100.0(45)$ & $100.0(63)$ & $100.0(135)$ & $100.0(164)$ \\
\hline \multicolumn{6}{|c|}{ Twin's own preference } \\
\hline Both equal & $29.6(8)$ & $44.9(22)$ & $17.9(12)$ & $29.4(42)$ & $30.4(52)$ \\
\hline Opposite poles & 0.0 & $2.0(1)$ & 0.0 & $0.7(1)$ & $0.6(1)$ \\
\hline Both mother's & $44.4(12)$ & $24.5(12)$ & $35.8(24)$ & $33.6(48)$ & $31.6(54)$ \\
\hline Both father's & $7.4(2)$ & $2.0(1)$ & 0.0 & $2.1(3)$ & $2.3(4)$ \\
\hline Equal and mother's & $18.5(5)$ & $22.4(11)$ & $38.8(26)$ & $29.4(42)$ & $29.8(51)$ \\
\hline Equal and father's & 0.0 & $4.1(2)$ & $7.5(5)$ & $4.9(7)$ & $5.3(9)$ \\
\hline Total & $100.0(22)$ & 100.0 (49) & $100.0(67)$ & $100.0(143)$ & 100.0 (171) \\
\hline
\end{tabular}

Note: ${ }^{1}$ Including all whose zygosity was known, ${ }^{2}$ Including also those with unknown zygosity.

Parental preference was also analyzed separately in different twin pairs (Table 1). Males of SS pairs experienced most often being equally close to both parents at all ages, and as many as $90 \%$ of $\mathrm{MZ}$ males had experienced equal preference before and at school age. Among MZ twins the equal parental preference continued longer, up to school age, after which an increase of maternal preference was seen.

Table 2 presents 'pairwise parental preference' and zygosity. About half of the twins experienced having been equally close to both parents, while about $30 \%$ were from 'equal and mother's' pair type. SS twins experienced most often being equally close to both parents, that is, 'both equal' and OS twins fell into the category 'equal and mother's' or 'both equal'. Being preferred by the father was uncommon at this age, pairs in which both were father's twins being particularly rare.

Depressive and psychosomatic symptoms in relation to parental preference at 22 to 30 years of age were evaluated separately in males and females. Males who reported (experienced parental preference) being equally close to both parents had the lowest total depressiveness score (mean 3.70, $n=135$ ), while males who experienced being preferred by the mother had most depressiveness $(5.65, n=51, p=.011$, Wald $F$ statistics for correlated data). In further analysis (Table 3a), a low total depressiveness score of equally preferred male twins was found especially among males in SS twin pairs. When analyzing these SS male twin pairs further, this difference of lower depressiveness and anhedonia of equally preferred twins remained significant only among SSDZ male pairs, not MZ ones. On the other hand, the highest self-confidence among equally preferred male twins was found only in OS twin pairs.

Female twins who were equally close to both parents had the highest self-confidence $(0.58, n=119)$ and least anhedonia $(0.96, n=115)$ and nervousness $(2.45, n=118)$. This difference was more evident when compared with those preferred by the mothers $(0.97$, $n=62, p=.02),(1.21, n=61, p=.05),(3.15, n=61$, $p=.01)$, respectively. The favorable situation of equally preferred female twins was especially prominent among OS females, as they reported the lowest total depressiveness score, highest self-confidence, least anhedonia and nervousness (Table $3 \mathrm{~b}$ ).

Depressive and psychosomatic symptoms were evaluated in relation to 'pairwise experienced parental preference' (Table 4). Highest depressiveness and lowest self-confidence were found among twins who were from 'both mother's' pairs.

\section{Twin's Own Preference}

Males felt more often equally close to both parents than female twins, while females in all twin types tended to feel closer to one of the parents, most often the mother. Differences in twins' own preference seemed to be in relation to twin's gender rather than zygosity. In general, SS males reported feeling equally close to both parents more often than OS males, and the difference was significant concerning twin's own preference in young adulthood. Among females there were no significant differences in distributions of parental preference between zygosity groups or different twin pairs (Table 1, Twin's own preference).

When the 'pairwise twin's own preference' was evaluated, about one third of the pairs were 'both equal', 
Table 3a

Depressive and Psychosomatic Symptoms in Relation to Experienced Parental Preference in Different Male Twin Groups at Twin's Age of 22 to 30 Years

\begin{tabular}{|c|c|c|c|c|}
\hline & Mother Mean $(n)$ & Equal Mean $(n)$ & Father Mean $(n)$ & $p^{*}$ \\
\hline \multicolumn{5}{|c|}{ Experienced parental preference } \\
\hline \multicolumn{5}{|l|}{ SS Males } \\
\hline Depressiveness & $5.57(21)$ & $3.57(93)$ & $1.00(4)$ & .056 \\
\hline Low self-confidence & $0.70(20)$ & $0.58(93)$ & $0.25(4)$ & $n s$ \\
\hline Anhedonia & $1.24(21)$ & $0.97(92)$ & $0.00(3)$ & .010 \\
\hline Sadness & $0.24(21)$ & $0.06(85)$ & $0.00(4)$ & .023 \\
\hline Nervousness & $3.05(21)$ & $2.33(91)$ & $1.50(4)$ & $n s$ \\
\hline Somatic symptoms & $0.67(21)$ & $0.52(92)$ & $0.25(4)$ & $n s$ \\
\hline \multicolumn{5}{|l|}{$\underline{M Z M}$} \\
\hline Depressiveness & $6.33(6)$ & $3.39(23)$ & $1.00(1)$ & $n s$ \\
\hline Low self-confidence & $0.67(6)$ & $0.57(23)$ & $0.00(1)$ & $n s$ \\
\hline Anhedonia & $1.67(6)$ & $0.83(23)$ & $0.00(1)$ & $n s$ \\
\hline Sadness & $0.33(6)$ & $0.05(22)$ & $0.00(1)$ & $n s$ \\
\hline Nervousness & $2.67(6)$ & $2.26(23)$ & $0.00(1)$ & $n s$ \\
\hline Somatic symptoms & $1.17(6)$ & $0.41(22)$ & $1.00(1)$ & $n s$ \\
\hline \multicolumn{5}{|l|}{$\underline{S S D Z M}$} \\
\hline Depressiveness & $5.90(10)$ & $3.33(49)$ & $0.50(2)$ & .063 \\
\hline Low self-confidence & $0.78(9)$ & $0.55(49)$ & $0.00(2)$ & $n s$ \\
\hline Anhedonia & $1.30(10)$ & $0.96(49)$ & $0.00(1)$ & .041 \\
\hline Sadness & $0.20(10)$ & $0.05(44)$ & $0.00(2)$ & $n s$ \\
\hline Nervousness & $3.90(10)$ & $2.19(47)$ & $1.50(2)$ & $n s$ \\
\hline Somatic symptoms & $0.50(10)$ & $0.51(49)$ & $0.00(2)$ & $n s$ \\
\hline \multicolumn{5}{|l|}{$\underline{\text { OS Males }}$} \\
\hline Depressiveness & $5.70(30)$ & $4.00(42)$ & $9.00(4)$ & $n s$ \\
\hline Low self-confidence & $1.00(30)$ & $0.44(41)$ & $2.67(3)$ & .029 \\
\hline Anhedonia & $1.27(30)$ & $1.15(39)$ & $1.50(4)$ & $n s$ \\
\hline Sadness & $0.28(29)$ & $0.26(34)$ & $1.00(3)$ & .053 \\
\hline Nervousness & $2.70(30)$ & $2.68(41)$ & $6.00(3)$ & $n s$ \\
\hline Somatic symptoms & $0.63(30)$ & $0.79(42)$ & $0.67(3)$ & $n s$ \\
\hline
\end{tabular}

Note: $p^{*}$ : Significances of differences in depressive and psychosomatic symptoms between parental preference groups were calculated. (Wald $F$ statistics for correlated data). Significance levels ${ }^{*} p<.05,{ }^{* *} p<.01$. < > indicates the significance between the two groups beside each other.

one third 'both mother's' and one third 'equal and mother's'. MZ twins fell most often into the category of 'both mother's' twin pair, SSDZ twins into the 'both equal' category, OS twins were most often from 'both mother's' or 'equal and mother's' pairs. The condition of feeling closest to the father was rare at this age, twin pairs in which both co-twins felt the father as the closer parent being particularly rare (Table 2, Twin's own preference).

Males who felt both parents to be equally close had the lowest total depressiveness score $(3.70, n=120)$ and least anhedonia $(0.94, n=114)$, and this difference was especially true when compared with those who felt the mother to be the closer parent $(5.32, n=66, p=.001)$, $(1.34, n=66, p=.03)$. When analyzing further different kinds of twin pairs, males of SS pairs who felt the mother to be the closer parent had the highest total depressiveness score and most anhedonia and sadness, while those SS males who felt the father to be closer had the lowest total depressiveness score and least anhedonia (Table 3c). The favorable situation of feeling both parents to be equally close was found among both MZ and SSDZ males. These males of MZ twin pairs who felt both parents to be equally close had lower total depressiveness score than those who felt the mother to be closer, while SSDZ males in intermediate situation reported less anhedonia and sadness than those who felt the mother to be closer. The intermediate situation of feeling both parents to be equally close also seemed beneficial for males of OS pairs as they had the lowest total depressiveness score and least nervousness. This difference was especially true in comparison with those OS males who felt the father to be the closer parent.

Females who felt equally close to both parents had least anhedonia $(0.79, n=71)$, and this difference was seen especially in comparison to those female twins 
Table $3 b$

Depressive and Psychosomatic Symptoms in Relation to Experienced Parental Preference in Different Female Twin Groups at Twin's Age of 22 to 30 Years

\begin{tabular}{|c|c|c|c|c|}
\hline & Mother Mean $(n)$ & Equal Mean $(n)$ & Father Mean $(n)$ & $p^{*}$ \\
\hline \multicolumn{5}{|c|}{ Experienced parental preference } \\
\hline \multicolumn{5}{|l|}{$\underline{\text { SS Females }}$} \\
\hline Depressiveness & $5.53(32)$ & $4.70(76)$ & $3.90(10)$ & $n s$ \\
\hline Low self-confidence & $0.91(32)$ & $0.61(76)$ & $0.40(10)$ & $n s$ \\
\hline Anhedonia & $1.00(31)$ & $1.03(73)$ & $1.10(10)$ & $n s$ \\
\hline Sadness & $0.13(31)$ & $0.30(76)$ & $0.20(10)$ & $n s$ \\
\hline Nervousness & $2.84(32)$ & $2.56(75)$ & $2.40(10)$ & $n s$ \\
\hline Somatic symptoms & $1.44(32)$ & $1.18(76)$ & $1.50(10)$ & $n s$ \\
\hline \multicolumn{5}{|l|}{$\underline{M Z F}$} \\
\hline Depressiveness & $6.60(10)$ & $3.50(18)$ & $3.00(4)$ & $n s$ \\
\hline Low self-confidence & $1.20(10)$ & $0.33(18)$ & $0.25(4)$ & $n s$ \\
\hline Anhedonia & $1.33(9)$ & $0.81(16)$ & $1.25(4)$ & $n s$ \\
\hline Sadness & $0.11(9)$ & $0.06(18)$ & $0.00(4)$ & $n s$ \\
\hline Nervousness & $2.60(10)$ & $1.83(18)$ & $2.00(4)$ & $n s$ \\
\hline Somatic symptoms & $1.60(10)$ & $1.06(18)$ & $1.50(4)$ & $n s$ \\
\hline \multicolumn{5}{|l|}{$\underline{S S D Z F}$} \\
\hline Depressiveness & $5.40(15)$ & $5.25(28)$ & $5.33(3)$ & $n s$ \\
\hline Low self-confidence & $0.80(15)$ & $0.71(28)$ & $0.33(3)$ & $n s$ \\
\hline Anhedonia & $0.87(15)$ & $1.11(27)$ & $1.67(3)$ & $n s$ \\
\hline Sadness & $0.20(15)$ & $0.32(28)$ & $0.67(3)$ & $n s$ \\
\hline Nervousness & $3.07(15)$ & $3.04(27)$ & $3.00(3)$ & $n s$ \\
\hline Somatic symptoms & $1.47(15)$ & $1.39(28)$ & $1.67(3)$ & $n s$ \\
\hline \multicolumn{5}{|l|}{$\underline{\text { OS Females }}$} \\
\hline Depressiveness & $6.40(30)$ & $3.40(43)$ & $6.67(3)$ & .070 \\
\hline Low self-confidence & $1.03(30)$ & $0.53(43)$ & $1.67(3)$ & .058 \\
\hline Anhedonia & $1.43(30)$ & $0.83(42)$ & $1.67(3)$ & .042 \\
\hline Sadness & $0.57(30)$ & $0.14(43)$ & $0.33(3)$ & $n s$ \\
\hline Nervousness & $3.48(29)$ & $2.26(43)$ & $3.67(3)$ & .013 \\
\hline Somatic symptoms & $1.10(30)$ & $1.42(43)$ & $0.67(3)$ & $n s$ \\
\hline
\end{tabular}

who felt the father to be the closer parent $(1.69$, $n=13, p=.03)$. In further analysis of different twin types this favorable situation of feeling equally close to both parents was found only in females of SS twin pairs (Table 3d).

When 'pairwise twin's own preference' was evaluated in relation to symptom reporting, no statistically significant differences were found (Table 4, Twin's own preference).

\section{Discussion}

As mothers participate increasingly in the labor market, fathers have become more involved in taking care of their children. This situation has also awakened an interest in the role of the father as caretaker. Twinship provides a unique opportunity to study implications of parenting styles as well as parental share on child's mental wellbeing. In the present study parental preference and its relation to mental health were examined in twins in young adulthood.

We found that the proportion of those twins who felt the mother to be the closer parent was about half (twin's own preference), while most twins felt being equally close to both parents (experienced parental preference) at all ages (Table 1). This kind of egalitarian attitude on the part of the parents towards both twins has also been found among twin infants (Moilanen et al., 2000). In families with young twins, both parents are very often needed in parenting and taking care of the children, and later on taking them to different activities and hobbies. This finding of equal parental preference might also show the egalitarian values of Finnish culture.

Earlier studies have given indications of the possible nature of the association between differential parenting on mental health in twin children and adolescents (Carbonneau et al., 2002; Dunn et al., 1990; Minde et 


\section{Table 4}

Depressive and Psychosomatic Symptoms in Relation to Pairwise Parental Preference in Twin Individuals

\begin{tabular}{|c|c|c|c|c|c|c|c|c|c|c|c|}
\hline \multirow{2}{*}{$\frac{\text { Pair type }}{\text { Individual twin }}$} & \multirow{2}{*}{$\begin{array}{c}\text { Both equal } \\
\text { Equal } \\
\text { Mean }(n)\end{array}$} & \multicolumn{2}{|c|}{ Opposite poles } & \multicolumn{2}{|c|}{ Same parent } & \multicolumn{2}{|c|}{ Equal - mother } & \multicolumn{2}{|c|}{ Equal - father } & \multirow{2}{*}{$\begin{array}{c}\text { Total } \\
\text { Mean }(n)\end{array}$} & \multirow[t]{2}{*}{$p^{*}$} \\
\hline & & $\begin{array}{c}\text { Mother } \\
\text { Mean }(n)\end{array}$ & $\begin{array}{c}\text { Father } \\
\text { Mean }(n)\end{array}$ & $\begin{array}{c}\text { Mother } \\
\text { Mean }(n)\end{array}$ & $\begin{array}{c}\text { Father } \\
\text { Mean }(n)\end{array}$ & $\begin{array}{c}\text { Equal } \\
\text { Mean }(n)\end{array}$ & $\begin{array}{c}\text { Mother } \\
\text { Mean }(n)\end{array}$ & $\begin{array}{c}\text { Equal } \\
\text { Mean }(n)\end{array}$ & $\begin{array}{c}\text { Father } \\
\text { Mean }(n)\end{array}$ & & \\
\hline Symptoms & \multicolumn{11}{|c|}{ Experienced parental preference } \\
\hline Depressiveness & $4.05(151)^{1}$ & $6.83(6)$ & $4.17(6)$ & $6.97(30)^{1,2}$ & $5.00(4)$ & $3.65(54)^{2}$ & $5.22(54)$ & $3.67(9)$ & $3.11(9)$ & $4.48(323)$ & $.007^{*}$ \\
\hline Low self-confidence & $0.56(151)^{3}$ & $0.80(5)$ & $0.40(5)$ & $1.30(30)^{3,4}$ & $0.25(4)$ & $0.50(54)^{4}$ & $0.85(54)$ & $0.89(9)$ & $0.89(9)$ & $0.68(321)$ & ns \\
\hline Anhedonia & $1.03(146)$ & $1.83(6)$ & $1.00(5)$ & $1.52(29)$ & $2.00(4)$ & $0.94(52)$ & $1.04(54)$ & $0.89(9)$ & $0.44(9)$ & $1.07(314)$ & .061 \\
\hline Sadness & $0.16(141)$ & $0.50(6)$ & $0.50(6)$ & $0.34(29)$ & $0.25(4)$ & $0.24(50)$ & $0.28(54)$ & $0.13(8)$ & $0.11(9)$ & $0.22(307)$ & ns \\
\hline Nervousness & $2.39(150)$ & $4.17(6)$ & $4.00(5)$ & $3.03(29)$ & $2.00(4)$ & $2.23(53)$ & $2.80(54)$ & $2.78(9)$ & $1.89(9)$ & $2.54(319)$ & $.049^{*}$ \\
\hline \multirow[t]{2}{*}{ Somatic symptoms } & $0.86(152)$ & $2.00(6)$ & $0.60(5)$ & $1.03(30)$ & $1.75(4)$ & $0.96(53)$ & $0.83(54)$ & $0.89(9)$ & $1.00(9)$ & $0.92(322)$ & $n s$ \\
\hline & \multicolumn{11}{|c|}{ Twin's own preference } \\
\hline Depressiveness & $4.09(101)$ & $3.00(1)$ & $11.00(1)$ & $5.02(104)$ & $3.00(8)$ & $3.92(51)$ & $5.56(50)$ & $3.44(9)$ & $3.13(8)$ & $4.53(333)$ & $n s$ \\
\hline Low self- confidence & $e 0.62(101)$ & $1.00(1)$ & $1.00(1)$ & $0.79(104)$ & $0.13(8)$ & $0.58(50)$ & $0.75(48)$ & $0.56(9)$ & $0.57(7)$ & 0.67 (329) & $n s$ \\
\hline Anhedonia & $0.90(96)$ & $1.00(1)$ & $3.00(1)$ & $1.17(103)$ & $1.13(8)$ & $0.98(49)$ & $1.32(50)$ & $0.78(9)$ & $0.88(8)$ & $1.07(325)$ & $n s$ \\
\hline Sadness & $0.13(95)$ & $0.00(1)$ & $2.00(1)$ & $0.25(101)$ & $0.13(8)$ & $0.26(47)$ & $0.35(48)$ & $0.13(8)$ & $0.25(8)$ & $0.23(317)$ & .054 \\
\hline Nervousness & $2.37(100)$ & $4.00(1)$ & $9.00(1)$ & $2.95(103)$ & $1.38(8)$ & $2.22(49)$ & $2.35(49)$ & $2.89(9)$ & $2.29(7)$ & $2.54(327)$ & $n s$ \\
\hline Somatic symptoms & $0.70(103)$ & $1.00(1)$ & $3.00(1)$ & $1.05(103)$ & $1.00(8)$ & $0.89(47)$ & $1.00(49)$ & $1.00(9)$ & $0.43(7)$ & $0.90(328)$ & $n s$ \\
\hline
\end{tabular}

Note: ${ }^{1} p=.011,{ }^{2} p=.011,{ }^{3} p=.005,{ }^{4} p=.012$ (in post hoc analysis Bonferroni's test significance levels were used).

$p^{*}$ differences between parental preference groups (Kruskal-Wallis Test).

al., 1990), but we have found only one study among adults (Baker \& Daniels, 1990). Consistent with research by Baker and Daniels (1990), our findings indicate that parental preference still continues to have implications on twins' wellbeing in young adulthood.

Egalitarianism seemed to be most beneficial for twins even now, in young adulthood, as intermediate positioned twins had the least depressive symptoms. Twins who experienced being equally close to both parents had least depressiveness, anhedonia and nervousness (experienced parental preference, Tables 3a and $3 \mathrm{~b}$ ). When analyzing the twin's own preference, the intermediate position, having an equally good relationship with both mother and father, seemed again the best position to be in, as these twins also reported least depressiveness and anhedonia (Tables $3 \mathrm{c}$ and $3 \mathrm{~d}$ ). One may assume that this egalitarian situation is easier for the parents when the burden of childcare has been shared, showing its positive effect now on the twins' wellbeing. In young adulthood this situation may reflect sufficient independence and a balanced adult relationship to both parents.

In general, mother's emotional presence is important for children and, for example, maternally disfavored twins have reported greater affect intensity and depression during adulthood than maternally favored co-twins (Baker \& Daniels, 1990). On the other hand, now in young adulthood, those twins who experienced being preferred by the mother had more depressive symptoms and nervousness than those in intermediate position (Tables $3 \mathrm{a}$ and $3 \mathrm{~b}$ ). In adolescence, among this same study group, mothers' favorites had had sleeping difficulties and other psychosomatic symptoms more often (Moilanen \& Pennanen, 1997), and this was then interpreted to be associated with the work of establishing independence as mothers usually have a tighter, more emotional parent-child bond, which is more difficult to break than a looser bond created by fathers who support independence. Furthermore, the present association between depression in the offspring and maternal preference in young adulthood might be due to the causes that originally led the mother to choose one of the twins as her favorite, as mothers may come to support and protect the weaker one.

In pairwise parental preference towards twins, it was surprising to find that in as many as 16 pairs both twins felt preferred by the mother and in two pairs by the father (Table 2). In further analysis twins who both experienced that they were preferred by the mother had the highest depressiveness and the lowest self-confidence (Table 4). We must keep in mind that this preference from the parental side is reported in young adulthood. We may assume that at this age mothers still maintain tighter contacts with their 'adult child' especially in situations where the child is having problems. We see a correlation between maternal preference and a higher degree of depressive symptoms reported, but we do not see the direction of the causality, which might be the opposite; the child's problems may give rise to maternal care and concern.

Male twins, especially those of SS pairs, who felt the mother to be the closer parent (twin's own preference) had most total depressiveness and anhedonia (Table 3c), while those female twins who felt the father to be closer showed slightly more depressive 
Table 3c

Depressive and Psychosomatic Symptoms in Relation to Twin's Own Preference on Parents in Different Male Twin Groups at Twin's Age of 22 to 30 Years

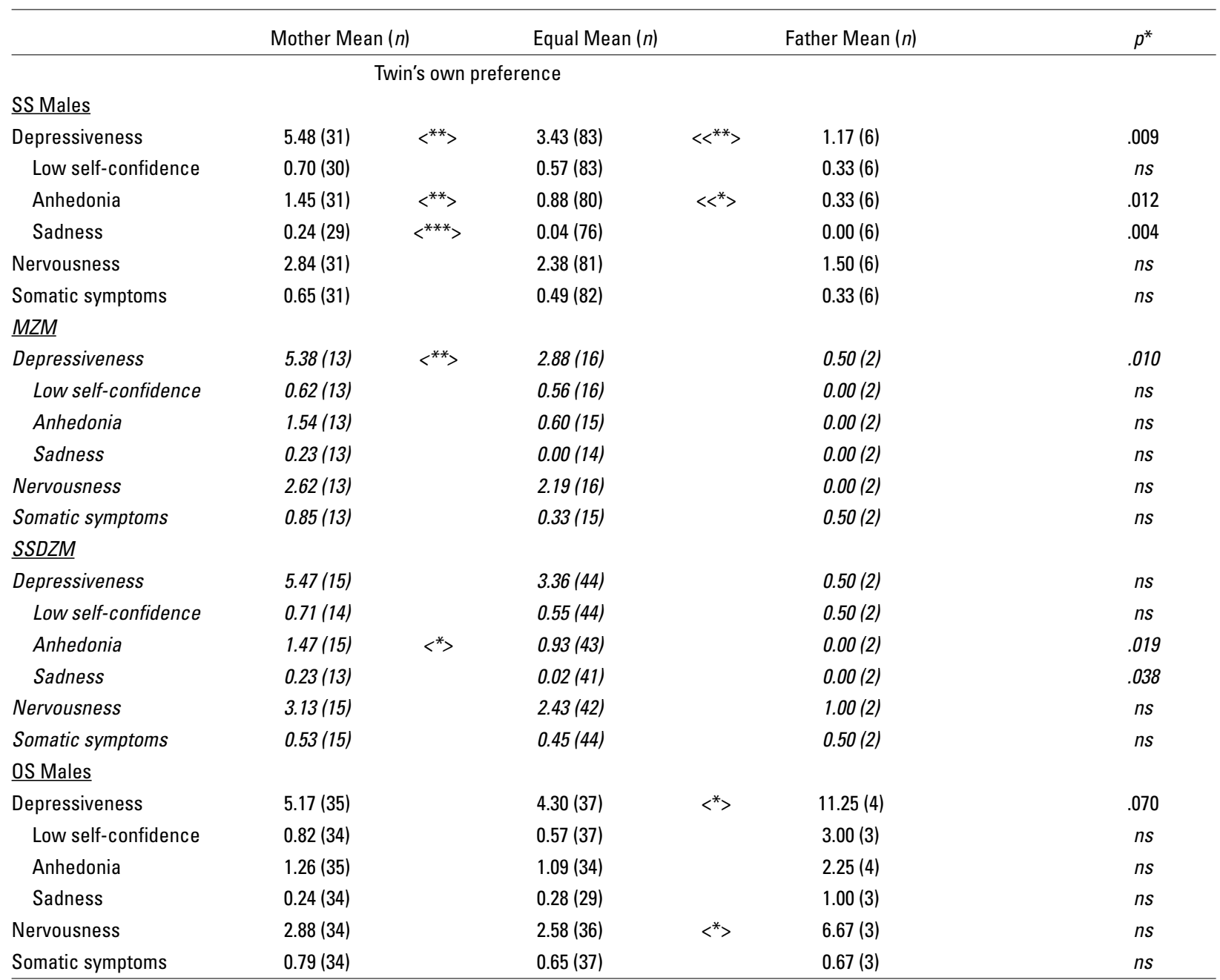

Note: $p^{*}$ : Significances of differences in depressive and psychosomatic symptoms between parental preference groups were calculated (Wald $F$ statistics for correlated data).

Significance levels ${ }^{*} p<.05,{ }^{* *} p<.01,{ }^{* * *} p<.001$. $<>$ indicates the significance between the two groups beside each other.

$\ll<$ indicates the significance between the two groups apart from each other.

and psychosomatic symptoms (Table $3 \mathrm{~d}$ ). While an equally good relationship to both parents seems to be reflecting the most balanced situation in adult life, a closer relationship to the opposite-sex parent may reflect difficulties in positive identification with the same-sex parent (Tyson \& Tyson, 1990). Twin's feeling of being closer to one of the parents might also be viewed as his/her experience of the other caregiver as insensitive and unresponsive, or feeling of deprivation of warmth and affection.

In further analysis, on the basis of zygosity of twin pairs, the small group of males in opposite-sex pairs who felt closest to the father (twin's own preference) had most depressiveness and nervousness (Table 3c). This was not seen among SS males. It is possible that when the relationship between the twin sister and the mother is close and tight, the male twin may feel excluded and lonely, and to compensate for this forms a closer relationship with the father. Because of the small number these connections have to be interpreted cautiously, without drawing hasty conclusions. However, it does seem beneficial to be equally close to both parents, as these twins reported the fewest symptoms.

The need to identify specific nonshared environmental influences among siblings arises from the behavior genetic evidence indicating that these factors account for the phenotypic variance on a variety of behavioral traits (Plomin, 1994). In accordance with past research (Allen et al., 1971; Carbonneau et al., 2002; Penninkilampi-Kerola et al., 2005), our findings indicate that the living environment is not the same for both twins. While MZ twins are genetically identical and live in the same family situation, they do nevertheless have different experiences, just like other twin types; they may, for example, be viewed and treated differently by their parents. Among others, 
Table 3d

Depressive and Psychosomatic Symptoms in Relation to Twin's Own Preference on Parents in Different Female Twin Groups at Twin's Age of 22 to 30 Years

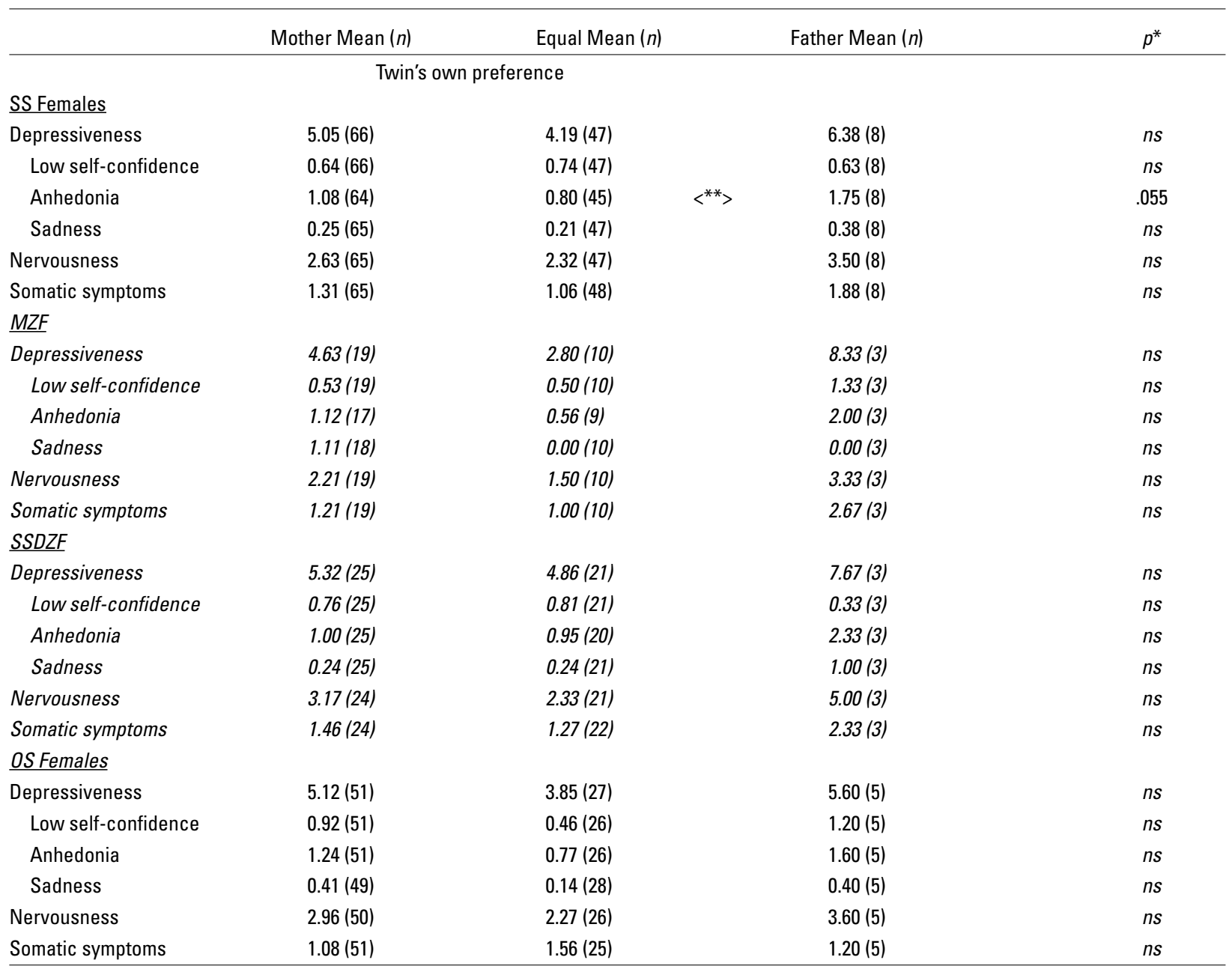

Note: $p^{*}$ : Significances of differences in depressive and psychosomatic symptoms between parental preference groups were calculated (Wald $F$ statistics for correlated data). Significance levels ${ }^{*} p<.05,{ }^{* *} p<.01$. $<>$ indicates the significance between the two groups beside each other.

being closer to the mother or to the father has an impact on the twin's mental wellbeing and should therefore possibly be included as a nonshared environmental factor in genetic analyses, especially on those related to mental health.

The present study has two limitations. First, the small number of twins in each zygosity group as well as in each parental preference group warrants some caution in the generalization of our results. Second, it would have been interesting to compare our findings in twins with those of singletons. This kind of comparison was carried out within the framework of a previous Finnish follow-up study from pregnancy to the beginning of school (Moilanen et al., 2000). Those twins who were taken care of equally by both parents were most often securely attached, while mothers' twins were more often of avoidant or defended attachment. In contrast, among singletons, mother's favorites seemed most often to be of secure attach- ment. In future, it would be worth investigating further whether the situation regarding parental preference is different for twins and singletons and whether this intermediate position is beneficial in adult singletons as well.

The following conclusion can be drawn about bringing up twins: the division of twins between parents should not be total, and it is important that both parents have a good relationship with both twins.

\section{Acknowledgment}

This work has been supported financially by the Alma and K. A. Snellman Foundation, Oulu, Finland.

\section{References}

Allen, M. G., Pollin, W., \& Hoffer, A. (1971). Parental, birth and infancy factors in infant twin development. American Journal of Psychiatry, 127, 33-39. 
Baker, L. A., \& Daniels, D. (1990). Non-shared environmental influences and personality differences in adult twins. Journal of Personality and Social Psychology, 58, 103-110.

Dunn, J., Stocker, C., \& Plomin, R. (1990). Nonshared experiences within the family: Correlates of behavioural problems in middle childhood. Development and Psychopathology, 2, 113-126.

Ebeling, H., Porkka, T., Penninkilampi-Kerola, V., Berg, E., Järvi, S., \& Moilanen, I. (2003). Inter-twin relationships and mental health. Twin Research, 6, 334-343.

Carbonneau, R., Lindon, J. E., Silberg, J. L., Siminoff, E., \& Rutter, M. (2002). Assessment of the within-family environment in twins: Absolute versus differential ratings, and relationship with conduct problems. Journal of Child Psychology and Psychiatry, 43, 1064-1074.

Holditch-Davis, D., Roberts, D., \& Sandelowski, M. (1999). Early parental interactions with and perceptions of multiple birth infants. Journal of Advanced Nursing, 30, 200-211.

Koivisto, M., Jouppila, P., Kauppila, A., Moilanen, I., \& Ylikorkala, O. (1975). Twin Pregnancy. III. Neonatal morbidity and mortality. Acta Obstetricia et Gynaecologica Scandinavica, (Suppl. 44), 21-29.

Kovacs, M. (1980). Rating scales assess depression in school-aged children. Acta Paedopsychiatrica, 46, 305-315.

Lytton, H. (1980). Parent-child interaction. The socialization process observed in twin and singleton families. New York: Plenum Press.

Minde, K., Corter, C., Goldberg, S., \& Jeffers, D. (1990). Maternal preference between premature twins up to age four. Journal of American Academy of Child and Adolescent Psychiatry, 29, 367-374.

Moilanen, I. (1979). To be born as a twin: Risks and sequelae (Doctoral thesis). Acta Universitatis Ouluensis, Series D Medica 50.

Moilanen, I. (1987). Dominance and submissiveness between twins. II. Consequences for mental health. Acta Geneticae Medicae et Gemellologiae, 36, 257-265.

Moilanen, I. (1990). Components of childhood depression. Reports of Psychiatria Fennica, 91, 85-91.
Moilanen, I., \& Pennanen, P. (1997). 'Mother's child' and 'father's child' among twins. Acta Geneticae Medicae et Gemellologiae, 46, 219-230.

Moilanen, I., Tirkkonen, T., Kunelius, A., \& Crittenden, P. (2000). Attachment in Finnish twins. In P. Crittenden \& A. Claussen (Eds.), The organization of attachment relationships: Maturation culture and context (pp. 125-140). New York: Cambridge University Press.

Penninkilampi-Kerola, V., Kaprio, J., Moilanen, I., \& Rose, R. J. (2005). Co-twin dependence and alcohol use: A population-based study of Finnish twins. Twin Research and Human Genetics, 8, 232-244.

Plomin, R. (1994). Genetic research and identification of environmental influences: Emanuel Miller Memorial Lecture. Journal of Child Psychology and Psychiatry, 35, 817-834.

Rimpelä, A., Rimpelä, M., \& Honkala, E. (1983). Sairastavuus, kuolleisuus ja koettu terveys. In M. Rimpela (Ed.), Health habits among Finnish youth. Series Original Reports 4 (pp. 191-207). Finland: Publications of the National Board of Health.

Rao, J. N. K., \& Scott, A. J. (1984). On chi-squared tests for multiway contingency tables with cell proportions estimated from survey data. The Annals of Statistics, 12, 46-60.

Robin, M., Kheroua, H., \& Casati, I. (1992). Effects of early mother-twin relationships from birth to age 3, on twin bonding. Acta Geneticae Medicae et Gemellologiae, 41, 143-148.

Sarna, S., Kaprio, J., Sistonen, P., \& Koskenvuo, M. (1978). Diagnosis of twin zygosity by mailed questionnaire. Human Heredity, 28, 241-254.

Sheehan, G. (1997). Adolescent sibling conflict: The role of the parental favouritism. Family Matters, 46, 37-39.

SPSS Inc. (2003). SPSS for Windows (Release 12.0) [Computer software]. Chicago, IL: SPSS, Inc.

StataCorp. (2003). Stata statistical software (Release 8.0) [Computer software]. College Station, TX: Stata Corporation.

Tyson, P., \& Tyson, R. L. (1990). Gender development: A theoretical overview. In P. Tyson \& R. L. Tyson (Eds.), Psychoanalytic theories of development ( $\mathrm{pp}$. 249-257). New Haven, London: Yale University Press. 